\title{
PERCEPÇÃO CRÍTICA SOBRE MATERIAL DIDÁTICO PARA A EDUCAÇÃO AMBIENTAL E O CONHECIMENTO POPULAR DO PARQUE NACIONAL DA SERRA DO ITAJAÍ
}

\author{
Jessica Kistner ${ }^{1}$ \\ Kleber Renan de Souza Santos ${ }^{2}$
}

Resumo: Considerando que a produção de materiais didáticos com informações científicas sobre Unidades de Conservação (UC) contribui para promover a Educação Ambiental (EA), este trabalho objetivou verificar a percepção popular sobre o Parque Nacional da Serra do Itajaí (PNSI), em Santa Catarina, e analisar o conteúdo de uma cartilha para fins de EA. Um formulário de pesquisa e a cartilha foram enviados de modo aleatório, via WhatsApp, para mais de 1000 contatos diversos, com 184 respondentes. A percepção sobre o parque e a cartilha foi positiva, porém, com sugestões para possíveis melhorias. Concluímos que é vantajoso o uso de mídias digitais e redes sociais para subsidiar ações de Educação Ambiental, científica e turismo no PNSI, especialmente no contexto da pandemia da Covid-19.

Palavras-chave: Divulgação Científica; Unidade de Conservação; Percepção Ambiental.

Abstract: Considering that the production of didactic materials with scientific information on Conservation Units (UC) contributes to promote Environmental Education (EA), this study aimed to verify the popular perception about the Serra do Itajaí National Park (PNSI), in Santa Catarina, Brazil, and analyze the contents of a Primer for the purposes of EA. A survey form and the booklet were sent at random, via WhatsApp, to more than 1000 different contacts, with 184 respondents. The perception of the park and the booklet was positive, however, with suggestions for possible improvements. We conclude that it is advantageous to use digital media and social networks to support environmental, scientific and tourism education actions in the PNSI, especially in the context of the Covid-19 pandemic.

Keywords: Scientific Divulgation; Conservation Unit; Environmental Perception.

${ }^{1}$ Centro Universitário Leonardo da Vinci - UNIASSELVI. E-mail: jessicabnu2@gmail.com,

Link para o Lattes: http://lattes.cnpq.br/6522910123134935

${ }^{2}$ Centro Universitário Leonardo da Vinci - UNIASSELVI. E-mail: kleber.renan.santos@gmail.com.

Link para o Lattes: http://lattes.cnpq.br/7710662933681863 


\section{Introdução}

O Parque Nacional da Serra do Itajaí (PNSI) é uma Unidade de Conservação Federal, criada pelo Decreto de 4 de junho de 2004, localizado nos municípios de Apiúna, Ascurra, Blumenau, Botuverá, Gaspar, Guabiruba, Indaial, Presidente Nereu e Vidal Ramos, no Estado de Santa Catarina, com uma área de 57.374 hectares (BRASIL, 2004). O Parque preserva o total de $2,5 \%$ da área remanescente de Mata Atlântica de Santa Catarina e representa a maior área contínua preservada do estado (BRASIL, 2009).

O propósito do PNSI é preservar amostra representativa do bioma Mata Atlântica e dos ecossistemas ali existentes, possibilitando a pesquisa científica e o desenvolvimento de atividades de Educação Ambiental e interpretação ambiental, de recreação em contato com a natureza e de turismo ecológico (BRASIL, 2004).

O Plano de Manejo do PNSI revela sua rica biodiversidade, com registros de 357 espécies de árvores, 220 de aves, 39 de anfíbios e 56 de mamíferos (BRASIL, 2009). Recentemente, um estudo documentou 230 espécies de epífitos vasculares na área do parque (CAGLIONI et al., 2015). Contudo, faltam estudos sobre os microrganismos, as microalgas, os fungos, a qualidade da água das lagoas, dentre outros aspectos relevantes para o melhor conhecimento desta unidade de conservação, dados que podem colaborar para promoção da Educação Ambiental e científica no parque.

Conforme afirmam Silva et al. (2016), existem várias formas de se promover a Educação Ambiental em unidades de conservação, entre elas está a produção de cartilhas didáticas educativas, que são informações que remetem ao leitor um cenário mais próximo da realidade e, dessa forma, ela possui uma grande capacidade para a promoção da Educação Ambiental, tornando-se um agente facilitador e um importante instrumento educacional formal e informal.

Considerando que a internet é um dos principais meios de comunicação da atualidade, o trabalho de Pinheiro (2003, p. 71), destaca que:

Um dos primeiros fenômenos observados, decorrente da Internet, foi a aproximação entre comunicação científica (de cientistas para cientistas) e divulgação científica [...] (comunicação de cientistas para a sociedade em geral).

Ou seja, é importante fazer bom uso da rede mundial de computadores para que o conhecimento chegue a toda população, em uma linguagem mais acessível e de fácil entendimento.

Diante da lacuna de estudos e de comunicação e divulgação científica sobre esta unidade de conservação, foi desenvolvido o Projeto ASAS - Água, Sedimentos, Algas e Solos do PNSI, o qual contribuiu com a produção de dados inéditos em cada um dos eixos de pesquisa. No eixo Água, foram

revista brasileira educação ambiental 
incluídos dados do Índice de Qualidade da Água (IQA) e Fitoplâncton (Algas) de três lagoas do parque. $O$ eixo Sedimentos apresentou a caracterização físico-química do sedimento das lagoas. Por fim, o eixo Solos incluiu os estudos de erosão nas imediações do PNSI e a diversidade de fungos do solo nos arredores das lagoas estudadas. Por meio desses eixos de pesquisa resultou-se em uma cartilha didática para Educação Ambiental (SANTOS et al. 2020, no prelo), que foi objeto de análise deste estudo.

Diante do exposto, as problemáticas que se pretendem responder com este trabalho são: qual é a percepção ambiental da comunidade do entorno do PNSI, em relação às características e importância desta unidade de conservação? Como a visitação ao PNSI pode contribuir para o aprendizado dos visitantes em relação às pesquisas realizadas no parque? Como uma cartilha didática pode contribuir para promover a Educação Ambiental e científica sobre o PNSI?

Assim, este trabalho teve como objetivos verificar a percepção popular sobre o Parque Nacional da Serra do Itajaí e analisar o conteúdo de uma cartilha elaborada pelo Projeto ASAS, com a finalidade de divulgar esse documento para subsidiar ações de Educação Ambiental, científica e turismo ecológico no PNSI.

\section{Materiais e Métodos}

Para diagnosticar o conhecimento do público sobre o PNSI e fazer uma análise crítica da cartilha do Projeto ASAS, foi realizada uma pesquisa digital, divulgada aleatoriamente, via WhatsApp, para aproximadamente 1000 contatos diversos (incluindo professores e alunos do ensino básico e superior e comunidade em geral), no período de 10 a 20 de maio de 2020. O questionário contou com 17 perguntas, sendo três sobre o perfil dos respondentes, 12 questões abertas, sobre conhecimento do PNSI e da cartilha e duas de múltipla escolha referente ao projeto ASAS e a cartilha (Apêndice 1). Trata-se, portanto, de uma pesquisa quali-quantitativa, conforme Souza e Kerbauy (2017).

$\mathrm{Na}$ mensagem de divulgação da pesquisa, foram explicados os objetivos e que se tratava de uma participação voluntária, assim, foram disponibilizados dois links: um para dar acesso à cartilha (no formato PDF) e outro para responder questões referentes ao PNSI e sobre a qualidade do material didático produzido (conforme questionário disponibilizado no Apêndice I).

A cartilha que foi divulgada durante a pesquisa foi elaborada em uma linguagem acessível, resumida e ilustrativa, totalizando nove páginas em sua versão original. Com as sugestões de melhoria provenientes desta pesquisa, a cartilha foi aperfeiçoada e submetida para publicação, e pode ser consultada na íntegra em Santos et al. (2020). 


\section{Resultados e discussão}

Participaram da pesquisa um total de 184 pessoas. Desse total, a maioria pertencia à faixa etária de 18 a 35 anos $(40,2 \% ; n=74)$ e de 36 a 50 anos (28,8\%; $n=53)$, e apenas um dos respondentes possuía mais de 70 anos $(0,5 \%)$, conforme detalhado na Tabela 1 . Esses dados demonstram a representatividade da pesquisa e correspondem, aproximadamente, à pirâmide etária brasileira e de Santa Catarina, conforme estimada pelo IBGE (2020).

No que diz respeito ao sexo, é possível notar que os respondentes do sexo feminino $(63,6 \% ; n=117)$ foram mais receptivos para responder 0 questionário (Tabela 1), considerando que para ler a cartilha e responder ao questionário leva em torno de 30 minutos.

Tabela 1: Perfil dos participantes da pesquisa $(n=184)$.

\begin{tabular}{lccc}
\hline Variável & Níveis da variável & $\begin{array}{c}\text { Número de } \\
\text { Respondentes }\end{array}$ & $\begin{array}{c}\% \text { de } \\
\text { Respondentes }\end{array}$ \\
\hline \multirow{4}{*}{ Idade } & Até 12 anos & 5 & $2,7 \%$ \\
& De 13 a 17 anos & 34 & $18,5 \%$ \\
& De 18 a 35 anos & 74 & $40,2 \%$ \\
& De 36 a 50 anos & 53 & $28,8 \%$ \\
Sexo & De a 70 anos & 17 & $9,2 \%$ \\
& Mais de 70 anos & 1 & $0,5 \%$ \\
\hline
\end{tabular}

Fonte: os autores (2020).

Os entrevistados foram também questionados quanto ao nível de escolaridade e, de acordo com a pesquisa, 23,9\% ( $n=44)$ estão cursando Ensino Médio, 22,8\% ( $n=42)$ estão cursando Ensino Superior, 20,1\% ( $n=37)$ possuem Superior Completo, 14,1\% $(n=26)$ possuem Especialização, 7,1\% $(n=13)$ estão cursando o Ensino Fundamental, 6\% ( $n=11)$ possuem Mestrado e $5,4 \%(n=10)$ possuem o título de Doutorado (Tabela 2), o que indica a relevância dos dados obtidos e a participação dos diversos públicos neste estudo. A elevada participação de estudantes do Ensino Médio e Superior (que somam $46,7 \%$ ) pode ser explicada pela rede de contatos dos pesquisadores, que possuem maior interação com estudantes e professores. 
Tabela 2: Escolaridade dos participantes da pesquisa $(n=184)$.

\begin{tabular}{lccc}
\hline Variável & Níveis da variável & $\begin{array}{c}\text { Número de } \\
\text { Respondentes }\end{array}$ & $\%$ de Respondentes \\
\hline & Cursando Ensino Fundamental & 13 & $7,1 \%$ \\
Escolaridade & Cursando Ensino Médio & 44 & $23,9 \%$ \\
& Cursando Ensino Superior & 42 & $22,8 \%$ \\
& Superior Completo & 37 & $20,1 \%$ \\
& Especialização & 26 & $14,1 \%$ \\
Mestrado & 11 & $6,0 \%$ \\
& Doutorado & 10 & $5,4 \%$ \\
\hline
\end{tabular}

Fonte: os autores (2020).

Dados relacionados ao conhecimento sobre o Parque Nacional da Serra do Itajaí e as contribuições da cartilha do Projeto ASAS para esse conhecimento são apresentados na Tabela 3.

Tabela 3: Visitação, leitura e localização do Parque Nacional da Serra do Itajaí ( $n=184)$.

\begin{tabular}{|c|c|c|c|}
\hline Variável & Níveis da variável & $\begin{array}{c}\text { Número de } \\
\text { Respondentes }\end{array}$ & $\%$ de Respondentes \\
\hline \multirow{3}{*}{$\begin{array}{l}\text { Você já visitou o Parque } \\
\text { Nacional da Serra do Itajaí, } \\
\text { o Parque das Nascentes } \\
\text { ou alguma outra área de } \\
\text { visitação do PNSI? }\end{array}$} & Sim & 93 & $50,6 \%$ \\
\hline & Não & 88 & $47,8 \%$ \\
\hline & Talvez & 3 & $1,7 \%$ \\
\hline \multirow{3}{*}{$\begin{array}{l}\text { Antes de conhecer a } \\
\text { cartilha do Projeto ASAS, } \\
\text { você já havia feito alguma } \\
\text { leitura sobre o PNSI? }\end{array}$} & Sim & 66 & $35,9 \%$ \\
\hline & Não & 113 & $61,4 \%$ \\
\hline & Talvez & 5 & $2,7 \%$ \\
\hline \multirow{3}{*}{$\begin{array}{l}\text { Antes de conhecer a } \\
\text { cartilha do Projeto ASAS, } \\
\text { você sabia onde o PNSI } \\
\text { está localizado e quais os } \\
\text { municípios abrangem sua } \\
\text { área geográfica? }\end{array}$} & Sim & 63 & $34,2 \%$ \\
\hline & Não & 112 & $60,9 \%$ \\
\hline & Talvez & 9 & $4,9 \%$ \\
\hline
\end{tabular}

Fonte: os autores (2020).

Os resultados demonstram que $50,6 \% \quad(n=93)$ dos entrevistados já visitaram o Parque Nacional da Serra do Itajaí, mais especificamente o Parque das Nascentes (Parque Natural Municipal Nascentes do Garcia, em Blumenau) ou alguma outra área de visitação do Parque Nacional, como o morro do Spitzkopf. Quando questionados sobre já ter realizado alguma leitura referente ao PNSI, $61,4 \%$ ( $n=113)$ responderam que não realizaram leitura alguma sobre o parque, e $60,9 \%(n=112)$ responderam que não sabem onde o PNSI está localizado e quais municípios abrangem sua área territorial (Tabela 3).

Esses dados demonstram a necessidade de realizar campanhas de divulgação sobre o PNSI, especialmente para a população dos municípios de seu entorno, com informações claras sobre esta unidade de conservação e os 
relevantes serviços ambientais proporcionados, como a preservação da biodiversidade, a regulação dos regimes de chuvas, umidade e clima regional, dentre outros benefícios para a qualidade de vida das pessoas e dos demais seres vivos.

Um dado curioso apontado pela pesquisa foi o fato de $50,6 \%(n=93)$ dos entrevistados terem visitado o PNSI e, apesar disso, um número mais elevado $(60,9 \% ; n=112)$ relatou não saber a localização do parque nem mesmo os municípios que abrangem sua área territorial. Essa informação aponta a necessidade de melhorar as visitações, com a implementação de programas de Educação Ambiental para os visitantes e de guias de parque, de modo a proporcionar maior interação dos visitantes com a história e informações científicas sobre essa unidade de conservação.

Para elaboração de um programa de Educação Ambiental para o PNSI, sugerimos, além das informações disponíveis na cartilha do Projeto ASAS (SANTOS et al., 2020), demonstrar a importância das unidades de conservação, conforme apontado no documento "Contribuição das unidades de conservação brasileiras para a economia nacional" (MEDEIROS et al., 2011), buscando transmitir essas informações de modo mais envolvente durante as visitações.

Foram questionados também se, antes de conhecer a cartilha do Projeto ASAS, eles já conheciam o Índice de Qualidade da Água (IQA), se sabiam o que são sedimentos e sua importância em uma lagoa, o que são algas e sua importância, e se saberiam dizer o que são fungos do solo (Tabela 4).

Tabela 4: Conhecimento dos respondentes sobre o índice de qualidade da água, os sedimentos em uma lagoa, as algas e a importância dos fungos do solo $(n=184)$.

\begin{tabular}{lccc}
\hline Variável & Níveis da variável & $\begin{array}{c}\text { Número de } \\
\text { Respondentes }\end{array}$ & $\%$ de Respondentes \\
\hline $\begin{array}{l}\text { Antes de conhecer a cartilha } \\
\text { do Projeto ASAS você }\end{array}$ & Sim & 53 & $28,8 \%$ \\
conhecia o Índice de & Não & 120 & $65,2 \%$ \\
Qualidade da Água (IQA)? & Talvez & 11 & $6,0 \%$ \\
\hline $\begin{array}{l}\text { Antes de conhecer a cartilha } \\
\text { do Projeto ASAS você sabia }\end{array}$ & Sim & 78 & $42,4 \%$ \\
$\begin{array}{l}\text { o que são sedimentos e qual } \\
\text { sua importância em uma }\end{array}$ & Não & 95 & $51,6 \%$ \\
lagoa? & Talvez & 11 & $6,0 \%$ \\
\hline $\begin{array}{l}\text { Antes de conhecer a cartilha } \\
\text { do Projeto ASAS você sabia }\end{array}$ & Sim & 95 & $51,6 \%$ \\
o que são algas e qual a sua & Não & 73 & $39,7 \%$ \\
importância? & Talvez & 16 & $8,7 \%$ \\
\hline $\begin{array}{l}\text { Antes de conhecer a cartilha } \\
\text { do Projeto ASAS você sabia }\end{array}$ & Sim & 86 & $46,7 \%$ \\
o que são fungos dos solos e & Não & 91 & $49,5 \%$ \\
qual a sua importância? & Talvez & 7 & $3,8 \%$ \\
\hline
\end{tabular}

Fonte: os autores (2020). 
Antes de conhecer a cartilha do Projeto ASAS, 65,2\% ( $n=120)$ dos entrevistados relataram não ter conhecimento sobre o índice de qualidade da água (IQA) (Tabela 4). Esse dado evidencia a contribuição da cartilha para promoção de um conhecimento relevante, que envolve o tema água e pode ser mais bem compreendido pelo público em geral.

O IQA foi desenvolvido com o objetivo de fornecer informações resumidas, simplificando relatórios complexos e com muitos dados de qualidade da água. É um mecanismo para a apresentação através de expressão numérica derivada de dados que define certo nível da qualidade da água (BORDALO; TEIXEIRA; WIEBE, 2006).

Considerando que a água é um tema transversal, trabalhado desde as séries iniciais até o Ensino Médio, esse dado demonstra a necessidade de as ações de Educação Ambiental buscarem integrar o conhecimento dos parâmetros e índices de qualidade mais utilizados pelas companhias de saneamento em nosso país, para contextualizar e aproximar os estudantes da sua própria realidade, facilitando a compreensão sobre a importância do monitoramento da qualidade da água e o conhecimento sobre o IQA.

Vale destacar os estudos realizados por Zumach (2003) e Zumach et al. (2006) sobre o enquadramento de curso de água: Rio Itajaí-Açu e seus principais afluentes em Blumenau e Monitoramento da qualidade da água do Ribeirão Garcia, respectivamente. Tais estudos contêm dados da região do PNSI e servem como documento sobre a qualidade da água naquele período investigado, revelando a melhor qualidade das águas nas áreas preservadas, dentro do PNSI, deteriorando conforme adentra nas áreas urbanizadas, indicando a relevância da preservação de áreas de mananciais bem como a continuidade dos estudos para garantir a conservação deste recurso fundamental à vida: a água.

Compreendemos a limitação de uma cartilha para contemplar todas essas informações, contudo, nossos dados apontam caminhos que poderiam colaborar para reflexão e melhoria de alguns processos de ensinoaprendizagem em Educação Ambiental, e que a leitura da cartilha do Projeto ASAS colaborou, ainda que sucintamente, para despertar a curiosidade e o aprendizado sobre esses temas.

Com relação aos sedimentos, $51,6 \% \quad(n=95)$ dos entrevistados não sabiam o que eram sedimentos e qual sua importância em uma lagoa, o que evidencia a contribuição da leitura da cartilha para promover, ainda que brevemente, esse aprendizado. Vale ressaltar que, o tema solo, abordado no sexto ano do Ensino Fundamental e retomado no Ensino Médio, envolve, de alguma maneira o conceito de sedimento, que nada mais é do que o solo abaixo dos corpos hídricos, e que pode ajudar a desvendar a reconstituição histórica dos corpos hídricos, como rios e lagoas, por exemplo, bem como de todo seu entorno. Esse dado demonstra uma lacuna de conhecimento sobre sedimentos na percepção dos entrevistados, apontando um tema interessante para ser abordado em ações de Educação Ambiental.

Revbea, São Paulo, V. 16, № 4: 18-35, 2021. 
Dos entrevistados, $51,6 \%$ ( $n=95)$ sabiam o que são algas e a sua importância em uma lagoa (Tabela 4). Apesar de ser o tema com maior percentual de conhecimento pelos respondentes da pesquisa, ainda é um valor muito baixo, se considerarmos que a importância das algas é tema trabalhado no sétimo ano do Ensino Fundamental e que 96,9\% dos entrevistados já concluíram esta fase escolar (Tabela 2).

De acordo com Matsumura-Tundisi (1999), os organismos aquáticos são vulneráveis às mudanças ambientais que resultam da introdução de poluentes orgânicos ou inorgânicos no meio através de atividades humanas. As espécies ou se adaptam às novas condições ou acabam se extinguindo pela falta de capacidade adaptativa às perturbações.

Especialmente os organismos planctônicos, como o fitoplâncton, respondem de imediato a essas perturbações e, muitas vezes, algumas espécies ou associações de espécies podem ser utilizadas como indicadores do estado trófico ou de ambientes que sofrem perturbações por atividades humanas. As mudanças no ambiente aquático, operando em uma variedade de frequências temporais, afetam a estrutura, a abundância e a produtividade da comunidade fitoplanctônica (REYNOLDS, 1990).

Com relação ao fitoplâncton (constituído por algas e cianobactérias), seria interessante elaborar um atlas fotográfico com as espécies mais comuns identificadas nas lagoas do PNSI. Para o estado de Santa Catarina e para o Brasil são escassos materiais didáticos com esta ênfase. Isso traria destaque à pesquisa com microalgas e ajudaria a despertar o interesse dos visitantes nesta temática.

Sobre os fungos do solo, $49,5 \%$ ( $n=91)$ dos respondentes não sabiam o que eram fungos do solo e sua importância (Tabela 4). A mesma observação apontada para o tema "algas" pode ser aplicada para o tema "fungos", que também é trabalhado no sétimo ano do Ensino Fundamental, e retomado no Ensino Médio.

O solo é um meio altamente complexo, com múltiplos componentes bióticos e abióticos, consistindo em vários microambientes. Consequentemente, os microrganismos e a fauna do solo ocupam vários nichos (BILLS et al., 2004).

Dentre os microrganismos que compõe a biomassa do solo, os fungos merecem destaque por se tratar do principal grupo decompositor da matéria orgânica complexa, degradando a celulose e lignina, além de outros polímeros amplamente encontrados em áreas florestais. São essenciais para a ciclagem e transporte de nutrientes para as plantas, além de exercer papel importante na supressão de doenças (THORN et al., 1996, DORAN; ZEISS, 2000; HILL et al., 2000).

Outro questionamento foi se, antes de cartilha, o entrevistado sabia da existência de três lagoas no PNSI, na região do Parque da Nascentes, conforme Tabela 5. 
Tabela 5: Conhecimento da existência de três lagoas no PNSI, na região do Parque das Nascentes pelos participantes da pesquisa $(n=184)$.

\begin{tabular}{lcccc}
\hline Variável & Níveis da variável & $\begin{array}{c}\text { Número de } \\
\text { Respondentes }\end{array}$ & $\%$ de Respondentes \\
\hline $\begin{array}{l}\text { Antes de conhecer a } \\
\text { cartilha do Projeto ASAS }\end{array}$ & Sim & 47 & $25,5 \%$ \\
$\begin{array}{l}\text { você sabia que existem } \\
\text { três lagoas no PNSI, na }\end{array}$ & Não & 136 & $73,9 \%$ \\
região do Parque das & Talvez & 1 & $0,5 \%$ \\
Nascentes?
\end{tabular}

Fonte: os autores (2020).

Conforme observado, grande parte dos entrevistados, 73,9\% ( $n=136)$, não sabiam da existência das três lagoas localizadas no PNSI, na região do Parque das Nascentes (Tabela 5), porcentagem muito elevada se considerarmos que 50,3\% ( $n=93)$ dos respondentes afirmaram já ter visitado o Parque das Nascentes ou alguma outra área do PNSI (Tabela 3). Esses dados indicam a relevância de se ter um documento didático que promova o conhecimento de modo mais integrado em relação às particularidades do Parque Nacional como um todo. Além disso, as pessoas que tiveram acesso à cartilha e responderam ao questionário provavelmente se lembrarão destas informações.

Com relação à cartilha, os resultados mostram que para $91,8 \%(n=169)$ dos entrevistados o conteúdo da cartilha do Projeto ASAS contribuiu para o seu aprendizado, 93,5\% ( $n=172)$ consideram que a ampla divulgação do material didático é positiva para promover a Educação Ambiental e científica, e 90,8\% $(n=167)$ recomendariam a leitura da cartilha para seus amigos (Tabela 6).

Tabela 6: Contribuição para o aprendizado, divulgação do material e recomendação da cartilha do Projeto ASAS $(n=184)$.

\begin{tabular}{lcccc}
\hline \multicolumn{2}{l}{ Variável } & Níveis da variável & $\begin{array}{c}\text { Número de } \\
\text { Respondentes }\end{array}$ & $\%$ de Respondentes \\
\hline $\begin{array}{l}\text { Você considera } \\
\text { conteúdo deste }\end{array}$ material & Sim & 169 & $91,8 \%$ \\
$\begin{array}{l}\text { contribuiu para o seu } \\
\text { aprendizado? }\end{array}$ & Não & 12 & $6,5 \%$ \\
\hline $\begin{array}{l}\text { Você considera que a } \\
\text { ampla divulgação deste }\end{array}$ & Sim & & $1,6 \%$ \\
material é positiva para & Não & 172 & $93,5 \%$ \\
promover a Educação & Talvez & 10 & $5,4 \%$ \\
Ambiental e científica? & & 2 & $1,1 \%$ \\
\hline $\begin{array}{l}\text { Você recomendaria a leitura } \\
\text { deste material para seus }\end{array}$ & Sim & 167 & $90,8 \%$ \\
amigos? & Não & 10 & $5,4 \%$ \\
\hline
\end{tabular}

Fonte: os autores (2020). 
Para identificar o potencial do material produzido, foram questionados aos entrevistados sobre a qualidade e conteúdo, e qual a melhor forma para leitura da cartilha. Os resultados obtidos encontram-se na Tabela 7.

Tabela 7: Opinião sobre a qualidade, conteúdo e forma de leitura da cartilha do Projeto ASAS

\begin{tabular}{lccc}
\hline Variável & Níveis da & & \\
& variável & $\begin{array}{c}\text { Número de } \\
\text { Respondentes }\end{array}$ & $\begin{array}{c}\% \text { de } \\
\text { Respondentes }\end{array}$ \\
\hline \multirow{4}{*}{ Na sua opinião, a qualidade e o } & Excelente & 129 & $70,1 \%$ \\
conteúdo do material é: & Boa & 53 & $28,8 \%$ \\
& Regular & 2 & $1,1 \%$ \\
& Ruim & 0 & $0,0 \%$ \\
& Péssima & 0 & $0,0 \%$ \\
\hline \multirow{4}{*}{ Na sua opinião, qual a melhor } & Celular & 78 & $42,4 \%$ \\
forma de ler a cartilha? & Computador & 48 & $26,1 \%$ \\
& Livro físico & 41 & $22,3 \%$ \\
& (impresso) & 17 & $9,2 \%$ \\
\hline
\end{tabular}

Fonte: os autores (2020).

Observou-se que $70,1 \%(n=129)$ dos entrevistados responderam que a qualidade e o conteúdo da cartilha do Projeto ASAS é excelente, $28,8 \%(n=53)$ consideraram boa, $1,1 \% \quad(n=2)$ classificaram como regular, e nenhum respondente considerou o material ruim ou péssimo (Tabela 7). Apesar desse dado positivo, temos a seguinte incógnita: por que $5,4 \% \quad(n=10)$ dos respondentes não recomendariam a leitura da cartilha para seus amigos? (conforme Tabela 6).

Uma explicação para esse dado pode estar relacionada ao nível de escolaridade, visto que todos os dez respondentes são estudantes do Ensino Médio. Provavelmente, para esse grupo de estudantes, a cartilha em seu formato original, com informações mais técnicas e temas pouco conhecidos não tenha despertado interesse para promover sua ampla divulgação e leitura para este público. Assim, os autores observaram com mais rigor as sugestões apontadas pelos entrevistados para melhoria da cartilha (conforme sintetizado na Tabela 8) e aperfeiçoaram o documento para publicação, buscando facilitar a linguagem sem perder o rigor técnico (SANTOS et al., 2020).

Vale ressaltar que mais de $90 \%$ dos respondentes recomendam a leitura da cartilha do Projeto ASAS para seus amigos e consideram que sua ampla divulgação contribui para promover a Educação Ambiental e científica do PNSI (Tabela 6).

Sobre a forma de leitura da cartilha, $42,4 \%(n=78)$ responderam que a melhor forma de leitura seria em celular, $26,1 \%(n=48)$ em computador, $22,3 \%$ ( $n=41)$ em livro físico, e 9,2\% (n=17) em leitor digital (Tabela 7). Esses dados mostram a preferência dos entrevistados pela leitura em celular e notebook, por 
serem meios mais versáteis e interativos, além de ser uma forma de comunicação mais sustentável, pois evita a impressão de papel e consequentemente poupa a exploração de árvores.

Contudo, consideramos que os $22,3 \%(n=41)$ dos entrevistados que preferem realizar a leitura da cartilha no formato de livro impresso é um valor expressivo, e isso demonstra a importância de não abandonarmos totalmente a utilização de materiais impressos para trabalhar com Educação Ambiental, de modo a garantir o acesso das informações para todos os públicos.

É perceptível a importância da Educação Ambiental quando nos referimos ao uso público em unidades de conservação. De acordo com Guimarães (2007), a Educação Ambiental mostra-se muito mais ampla que o mero ensino da ecologia ou a descrição de problemas ambientais. É necessário um aprofundamento na reflexão para que as práticas se concretizem em uma Educação Ambiental crítica.

Segundo a Política Nacional de Educação Ambiental, Lei n 9.795/1999, Art $1^{\circ}$, destaca-se como conceito de Educação Ambiental:

Entendem-se por Educação Ambiental os processos por meio dos quais o indivíduo e a coletividade constroem valores sociais, conhecimentos, habilidades, atitudes e competências voltadas para a conservação do meio ambiente, bem de uso comum do povo, essencial à sadia qualidade de vida e sua sustentabilidade (BRASIL, 1999, s.p.).

Sendo assim, a divulgação da cartilha do Projeto ASAS (SANTOS et al., 2020), colabora para a efetivação da Educação Ambiental se utilizada de maneira adequada, bem como contribui para o Objetivo de Desenvolvimento Sustentável número 4, ODS4 da Organização das Nações Unidas (ONU, 2018), de promover a educação para todos, e para promoção do conhecimento em Educação Ambiental. Com a publicação da cartilha do Projeto ASAS sua amplitude de acesso será ainda maior e permanente, cabendo aos pesquisadores e educadores ambientais atualizarem seu conteúdo e ampliarem os estudos no PNSI.

Com relação às sugestões, críticas e elogios sobre a cartilha do Projeto ASAS, os dados foram compilados na Tabela 8. Os comentários repetidos foram eliminados e foi adicionado a informação de quantas vezes eles foram citados pelos entrevistados. 
Tabela 8: Opinião de alguns entrevistados em relação a pergunta: você gostaria de fazer alguma sugestão, elogio ou crítica sobre a cartilha do Projeto ASAS?

\begin{tabular}{|c|c|c|}
\hline Opinião & $\begin{array}{c}\mathbf{N}^{\circ} \text { de } \\
\text { vezes } \\
\text { que } \\
\text { foi } \\
\text { citado }\end{array}$ & Classificação \\
\hline Trabalho muito interessante para a nossa população & 2 & Elogio \\
\hline A cartilha é muito boa, valoriza a biodiversidade e geografia local & 1 & Elogio \\
\hline $\begin{array}{l}\text { As informações da cartilha são excelentes para melhorar o } \\
\text { conhecimento sobre o PNSI }\end{array}$ & 3 & Elogio \\
\hline A cartilha está muito boa, ótima didática & 7 & Elogio \\
\hline Estudo de grande valor para a Educação Ambiental crítica & 1 & Elogio \\
\hline Muito bem ilustrado, objetivo, claro e de fácil entendimento & 4 & Elogio \\
\hline O teor científico é excelente & 1 & Elogio \\
\hline Super didática, prática e de fácil entendimento & 2 & Elogio \\
\hline $\begin{array}{l}\text { Toda forma de divulgação sobre o que nos cerca como este parque é } \\
\text { muito importante }\end{array}$ & 1 & Elogio \\
\hline $\begin{array}{l}\text { Ótima iniciativa, pouco se fala sobre essa importante unidade de } \\
\text { conservação }\end{array}$ & 2 & Elogio \\
\hline Distribuir a cartilha de forma a transformar a curiosidade & 1 & Sugestão \\
\hline Disponibilizar a cartilha para escolas & 2 & Sugestão \\
\hline Disponibilizar a cartilha com maiores ilustrações & 1 & Sugestão \\
\hline Ampliar a amostragem de pesquisa & 1 & Sugestão \\
\hline $\begin{array}{l}\text { Poderia ser impressa para ser usada em escolas de Ensino } \\
\text { Fundamental e Médio }\end{array}$ & 3 & Sugestão \\
\hline $\begin{array}{l}\text { Conectar os resultados do estudo com a importância da proteção do } \\
\text { bioma }\end{array}$ & 1 & Sugestão \\
\hline Recomendo menos texto e mais desenhos e/ou fotografias & 1 & Sugestão \\
\hline $\begin{array}{l}\text { Para ser mais didático seria necessário fracionar a gama de } \\
\text { informações }\end{array}$ & 1 & Sugestão \\
\hline Seria interessante relacionar o IQA das lagoas com estudos locais & 1 & Sugestão \\
\hline Usar uma linguagem menos técnica & 1 & Sugestão \\
\hline Inserir foto das algas e fungos mais comuns & 1 & Sugestão \\
\hline
\end{tabular}

Fonte: Os autores (2020).

Os entrevistados descreveram em suas respostas que a cartilha está de fácil entendimento, didática e excelente para a divulgação do Parque Nacional da Serra do Itajaí. Porém, sugeriram uma linguagem menos técnica, fracionando a gama de informações. Grande parte dos entrevistados sugeriram disponibilizar a cartilha para as escolas de Ensino Fundamental e Médio, incentivando a Educação Ambiental e o conhecimento do PNSI (Tabela 8).

Foi sugerido ampliar a amostragem da pesquisa, incluindo a proteção do bioma e a inclusão de mais desenhos e/ou fotografias. Elogiaram quanto a iniciativa, pois, segundo os entrevistados, pouco se fala sobre esta unidade de conservação, valorizando, assim, a biodiversidade e geografia da região. Em 
síntese, 63,2\%, elogiaram a cartilha do Projeto ASAS e 36,8\% fizeram sugestões para o seu aperfeiçoamento e melhoria.

Conforme citado por Valerio e Pinheiro (2008), o conceito de Comunicação Científica foi definido por Garvey e Grifit em 1979 como o conjunto de atividades associadas à produção, disseminação e uso da informação por especialistas. Na fase da pesquisa, ocorre a geração da informação e a disseminação se dá pela transferência da informação por meio de canais de comunicação heterogêneos, os quais podem ser formais ou informais, orais ou escritos.

Em outras palavras, Bueno (2010) afirma que:

A comunicação científica mobiliza o debate entre especialistas como parte do processo natural de produção e legitimação do conhecimento científico. A divulgação científica, por sua vez, busca permitir que pessoas leigas possam entender, ainda que minimamente, o mundo em que vivem e, sobretudo, assimilar as novas descobertas, o progresso científico, com ênfase no processo de educação científica, ou seja, consiste na divulgação das informações científicas ao público leigo (BUENO, 2010, p. 5).

Em 2015, países-membros da ONU adotaram o documento "Transformando o Nosso Mundo: A Agenda 2030 para o Desenvolvimento Sustentável", constituído por 17 Objetivos de Desenvolvimento Sustentável, os ODS, com o intuito de erradicar a pobreza e promover uma vida digna para todas as pessoas. O ODS 4 tem como objetivo propiciar uma educação inclusiva para todos, além de ser equitativa e de qualidade, promovendo oportunidades de aprendizagem ao longo da vida para todos (ONU, 2018). Nesse sentido, a divulgação da cartilha do Projeto ASAS contribui para efetivação do ODS 4, possibilitando aos diversos públicos o acesso a informações científicas sobre uma unidade de conservação de importância regional e nacional.

Vale destacar que o uso das redes sociais tem se mostrado como um canal de comunicação eficiente por envolver um maior número de usuários, de diversas idades, sem utilização de papel impresso, o que representa uma forma de comunicação mais sustentável.

Além disso, a utilização desse material didático permite o exercício da Educação Ambiental formal e informal, atuando como uma metodologia alternativa de ensino, pois nesses locais os conceitos biológicos e científicos podem ser trabalhados de forma divertida e prática, por exemplo, assim como documentado por Nhaga, Camarotti e Correia (2021), para o Parque Nacional de Sete Cidades, no estado do Piauí. São produções que contribuem para efetivação da Educação Ambiental em unidades de conservação. 
Considerando que os conteúdos científicos podem ser mais atrativos e interessantes, impulsiona, através das vivências, exploração e curiosidades, desenvolvendo o sentimento de preservação e motivando os alunos e visitantes ao aprendizado (SILVA; MENDES, 2014). Com um texto de fácil entendimento, a cartilha pode obter resultados ótimos em seu propósito, podendo ser aplicada tanto em atividades voltadas para o público infantil, quanto como instrumento educativo ao público em geral (SILVA et al., 2017; NASCIMENTO et al., 2020).

\section{Conclusões}

A realização da pesquisa de opinião sobre a cartilha do Projeto ASAS e sobre o conhecimento do Parque Nacional da Serra do Itajaí contribuiu para o aperfeiçoamento da cartilha, acrescentando informações e ilustrações para complementar o seu conteúdo e, ao revelar que mais da metade dos entrevistados não conhecem o PNSI, possibilitou ampliar a discussão sobre Educação Ambiental crítica, propondo melhoria contínua nos processos de visitação, despertando nos entrevistados a curiosidade e o encantamento pelo PNSI, etapas-chave para sensibilização e conscientização socioambiental.

Além disso, sugerimos utilizar-se dos diferentes meios de comunicação, especialmente os digitais e redes sociais para promover a divulgação científica sobre o PNSI e tornar as informações acadêmicas mais acessíveis à população através da divulgação científica.

Por fim, as discussões apresentadas neste trabalho podem servir de subsídio para o desenvolvimento e aperfeiçoamento de programas de Educação Ambiental no PNSI e para inspirar outras ações em diferentes unidades de conservação.

\section{Agradecimentos}

Ao Programa de Bolsas Universitárias de Santa Catarina (UNIEDU), pela bolsa concedida à primeira autora (JK). Ao Dr. Eder Caglioni pela leitura crítica e sugestões construtivas. Aos revisores anônimos que contribuíram para melhoria deste manuscrito.

\section{Referências}

BILLS, G.F. et al. Biodiversity of fungi Inventory and monitoring methods. Amsterdam: Elsevier, 2004. p. 271-302.

BORDALO, A.A.; TEIXEIRA, R.; WIEBE, W.J.A Water Quality Index Applied to an International Shared River Basin: The Case of the Douro River. Environmental Management, v. 38, p. 910-920, 2006. 
BRASIL. Decreto $s / n^{\circ}$ de 4 de junho de 2004. Cria o Parque Nacional da Serra do Itajaí, nos Municípios de Ascurra, Apiúna, Blumenau, Botuverá, Gaspar, Guabiruba, Indaial, Presidente Nereu e Vidal Ramos, no Estado de Santa Catarina, e dá outras providências. 2004. Disponível em: $<$ https://www.planalto.gov.br/ccivil 03/ ato2004-2006/2004/dnn/dnn10203.htm >. Acesso em: 7 jun. 2020.

BRASIL. Ministério da Educação e do Desporto. Lei n 9.795 de 27 de abril de 1999. Dispõe sobre a Educação Ambiental, institui a Política Nacional de Educação Ambiental e dá outras providências. 1999. Disponível em: http://www.planalto.gov.br/ccivil_03/leis/19795.htm. Acesso em: 7 jun 2020.

BRASIL. Plano de Manejo Parque Nacional Serra do Itajaí. Brasília: Ministério do Meio Ambiente, Instituto Chico Mendes da Conservação da Biodiversidade, 2009. 765 p. Disponível em: $<$ https://www.icmbio.gov.br/portal/images/stories/imgs-unidadescoservacao/pn serra do itaja\%C3\%AD.pdf>. Acesso em: 18 jun. 2020.

BUENO, C. W. Comunicação científica e divulgação científica: Aproximações e rupturas conceituais. Informação \& Informação, Londrina, v. 15, supl, p. 112, 2010.

CAGLIONI, E. et al. Riqueza de epífitos vasculares do Parque Nacional da Serra do Itajaí - Santa Catarina. In: $66^{\circ}$ CONGRESSO NACIONAL DE BOTÂNICA, 66, 2015, São Paulo. Anais [...] Santos/São Paulo, 2015. Disponível em: $<$ https://ainfo.cnptia.embrapa.br/digital/bitstream/item/174266/1/CNPASA2015-cnb.pdf>. Acesso em: 18 jun. 2020.

DORAN, J. W.; ZEISS, M. R. Soil health and sustainability: managing the biotic componente of soil quality. Applied Soil Ecology, Amsterdam, v. 1, p. 3-11, 2000.

GARVEY, W. D.; GRIFFITH, B. C. Communication, the essence of science, Apêndice A, B. In: GARVEY, W. D. Communication: the essence of science. Oxford: Pergamon Press, 1979. p. 299. Disponível em: <http://globalreach.biz/globstats/evol.html>. Acesso em: 18 jun. 2020.

GUIMARÃES, M. Educação Ambiental: participação para além dos muros da escola. In: MELLO, S.; TRAJBER, R. (orgs.). Vamos cuidar do Brasil: conceitos e práticas em Educação Ambiental. Brasília: MEC/UNESCO, 2007.

HILL, G. T. et al. Methods for assessing the composition and diversity of soil microbial communities. Applied Soil Ecology, Amsterdam, v 15, p. 25-36, 2000.

IBGE. Brasil e Santa Catarina: Pirâmide etária 2010-2060. 2020. Disponível: $<$ https://www.ibge.gov.br/apps/populacao/projecao/box piramideplay.php?ag= 42>. Acesso em: 18 jun. 2020. 
MATSUMURA-TUNDISI, T. Diversidade de zooplâncton em represas do Brasil. cap. 2, p. 41-54. In: HENRY, R. Ecologia de reservatórios: estrutura, função e aspectos sociais. Botucatu, SP, FUNDBIO: FAPESP, 1999.

MEDEIROS, R. et al. Contribuição das unidades de conservação brasileiras para a economia nacional: Sumário Executivo. Brasília: UNEPWCMC, $44 \quad$ p., $2011 . \quad$ Disponível em: $<$ https://www.icmbio.gov.br/portal/images/stories/comunicacao/estudocontribuic ao.pdf $>$. Acesso em: 18 jun. 2020.

NHAGA, T.; CAMAROTTI, M. de F.; CORREIA, M. L. D. Subsídios para implantação da Educação Ambiental no Parque Nacional de Sete Cidades (PI) por meio da percepção dos moradores de uma comunidade do entorno. Revista Brasileira de Educação Ambiental, São Paulo, v. 16, n. 1, p. 527547, 2021.

ORGANIZAÇÃO DAS NAÇÕES UNIDAS. ODS4. Educação de qualidade. 2018. Disponível em: <https://nacoesunidas.org/pos2015/ods4/>. Acesso em: 20 mai. 2020.

PINHEIRO, L. V. R. Comunidades científicas e infraestrutura tecnológica no Brasil para uso de recursos eletrônicos de comunicação e informação na pesquisa. Ciência da Informação, Brasília, v. 32, n. 3, p. 62-73, 2003.

PROJETO ASA'S. Água, Sedimento e Algas do Parque Nacional da Serra do Itajaí. Submetido ao Edital 01/2018 do SOS Mata Atlântica. Curso de Engenharia Ambiental. Indaial: UNIASSELVI, 2008. 10 p.

REYNOLDS, C. S. Temporal scales of variability in pelágic environments ans the response of phytoplankton. Freshwater Biology, v. 23, p. 25-53, 1990.

SANTOS, K. R. S. et al. Projeto ASAS: Água, Sedimentos, Algas e Solos do Parque Nacional da Serra do Itajaí. Revista Maiêutica - Engenharias, Indaial, v. 5 , n. 01 , p. $57-68,2020$.

SILVA, D. B.; MENDES, R. L. Preparação do guia didático trilha históricoecológica no museu da vida por licenciando em biologia da faculdade de formação de professores da UERJ: buscando a emoção e a reflexão dos alunos. Revista de Ensino de Biologia da SBEnBio. Rio de Janeiro. v. 1, n. 7, 2014.

SILVA, G. R. D. et al. Proposta de guia e cartilha Didática para subsidiar o ecoturismo no Parque Nacional da Furna Feia, Mossoró/RN. In: I CONDIS... Anais [...] Campina Grande: Realize Editora, 2016. Disponível em: <https://editorarealize.com.br/artigo/visualizar/24118>. Acesso em: 6 fev. 2019.

SILVA, K. A. et al. Elaboração de uma cartilha como material educativo para preservação da tartaruga verde (Chelonia mydas) em Itaipú, Niterói, Rio de Janeiro. Revista Presença, [S.I.], v. 2, p. 35-58, 2017. 
SOUZA, K. R.; KERBAUY, M. T. M. Abordagem quanti-qualitativa: superação da dicotomia quantitativa-qualitativa na pesquisa em educação. Educação e Filosofia, v. 31, n. 61, p. 21-44, 2017.

THORN, R. G. Isolation of saprophytic basidiomycetes from soil. Applied and Environmental Microbiology, Washington, v. 62, p. 4288-4292, 1996.

VALERIO, P. M.; PINHEIRO, L. V. R. Da comunicação científica à divulgação. Tranisformação, Campinas, v. 2, n. 20, p. 159-169, 2008.

ZUMACH, R. Enquadramento de curso de água: Rio Itajaí-Açu e seus principais afluentes em Blumenau. 2003. Dissertação (Mestrado em Engenharia Ambiental) - Programa de Pós-Graduação em Engenharia Ambiental, Universidade Federal de Santa Catarina, Florianópolis. Disponível: $<$ https://repositorio.ufsc.br/bitstream/handle/123456789/86351/200163.pdf?seq uence $=1$ \&isAllowed $=\mathrm{y}>$. Acesso em: 18 jun. 2020.

ZUMACH, R. et al. Monitoramento da qualidade da água do Ribeirão Garcia Blumenau/SC. In: I SIMPÓSIO DE RECURSOS HÍDRICOS DO SULSUDESTE, 2006, Curitiba. Anais [...] Curitiba, 2006. p. 1-17. 


\section{APÊNDICE I - Formulário de pesquisa}

1) Idade

a) Até 12 anos

b) De 13 a 17 anos

c) De 18 a 35 anos

d) De 36 a 50 anos

e) De 51 a 70 anos

f) Mais que 70 anos

2) Sexo

a) Masculino

b) Feminino

3) Escolaridade

a) Cursando Ensino Fundamental

b) Cursando Ensino Médio

c) Cursando Ensino Superior

d) Superior completo

e) Especialização

f) Mestrado

g) Doutorado

4) Você já visitou o Parque Nacional da Serra do Itajaí, o Parque das Nascentes ou alguma outra área de visitação do PNSI?

5) Antes de conhecer a cartilha do Projeto ASAS você já havia feito alguma leitura sobre o Parque Nacional da Serra do Itajaí?

6) Antes de conhecer a cartilha do Projeto ASAS você sabia onde o PNSI está localizado, quais os municípios abrangem sua área geográfica?

7) Antes de conhecer a cartilha do Projeto ASAS você conhecia o Índice de Qualidade da Água (IQA)?

8) Antes de conhecer a cartilha do Projeto ASAS você sabia o que são sedimentos e qual a sua importância em uma lagoa?

9) Antes de conhecer a cartilha do Projeto ASAS você sabia o que são algas e qual a sua importância?
10) Antes de conhecer a cartilha do Projeto ASAS você sabia o que são fungos dos solos e qual a sua importância?

11) Antes de conhecer a cartilha do Projeto ASAS você sabia que existem três lagoas no PNSI, na região do Parque das Nascentes?

12) Agora que você conheceu a cartilha do Projeto ASAS você considera que o conteúdo deste material contribuiu para o seu aprendizado?

13) Agora que você conheceu a cartilha do Projeto ASAS você considera que a ampla divulgação deste material é positiva para promover a Educação Ambiental e científica?

14) Agora que você conheceu a cartilha do Projeto ASAS você recomendaria a leitura deste material para seus amigos?

15) Agora que você conheceu a cartilha do Projeto ASAS, na sua opinião, a qualidade e conteúdo do material é:
a) Excelente
b) Boa
c) Regular
d) Ruim
e) Péssima

16) Agora que você conheceu a cartilha do Projeto ASAS, na sua opinião, qual a melhor forma de ler a cartilha?
a) Livro físico (impresso)
b) Computador
c) Leitor digital
d) Celular

17) Você gostaria de fazer alguma sugestão, elogio ou crítica sobre a cartilha do Projeto ASAS? Sua opinião é muito importante. 